\title{
ALTERNATIVE FUEL CONSUMPTION MEASUREMENT DEVICE FOR MULTIPURPOSE FARM MACHINERY USE
}

\author{
A.M. Elsbaay ${ }^{\mathrm{i}} \quad$ R. A. Hegazy ${ }^{\mathrm{ii}}$
}

\begin{abstract}
Measuring fuel consumption of deferent farm machines is essential step and requires recommended level of accuracy. However, the majorities of methods which are being used now in Egypt are still inaccurate enough and depend more on unacceptable methods. So, in this study, the fuel consumption device was designed and built to measure the fuel consumed by farm machines also used in wide range of related applications. Major components of the designed fuel consumption device were turbine type flow sensors, electronic board and circuits, power source (common 12 volt battery available in agricultural vehicles), built-in storage memory, interfaces and display facilities, connecting wires and housing. Turbine flowmeters Vision 1000 sensors have been used to build the fuel consumption device which have very small flowrates of $0.05-2.5 \mathrm{l} / \mathrm{min}$. Electronic board used in the study was a modified version of ATmega328 series chip. The pulses of the flow sensors are being converted into consumption and displayed Liquid crystal display (LCD) screen has been attached with multi capacity memory card and USB interface. The device has been calibrated with standard method of using volumetric flow rate recorded through precise device made for that purpose. $110 \mathrm{hp} \mathrm{New}$ Holland tractor and a $16 \mathrm{hp}$ medium size engine have been used for tracing the accuracy and differences of using fuel consumption device at stationery mode. In field, the fuel consumption device attached to two different machines, a $58 \mathrm{hp}$ Claas combine harvester tested on ground with no crop. Second farm machine was the New Holland tractor $110 \mathrm{hp}$ running in field alone and loaded with disc plough, to show the differences appear during different conditions for more reliability for fuel measurement device. Results showed that for the tractor, there were acceptable linear relationships between real volumetric consumption of
\end{abstract}

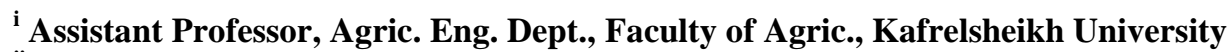

ii Associate Professor, Agric. Eng. Dept., Faculty of Agric., Kafrelsheikh University 
fuel flow and volume measured by the fuel flow device with $0.8 \%$ differences between averages at full throttle, and $0.16 \%$ differences between averages at lower throttle. For $16 \mathrm{hp}$ engine tested in lab, the differences were higher and around $1.5 \%$ and $2.4 \%$ in case of running the engine at full throttle and lower throttle position respectively. For recording the tractor fuel consumption in field, increasing both forward speed and load equipped with it increased fuel consumption. Where, attaching disc plough to the tractor increased the fuel consumed by the engine by $20.75 \%$ at low tractor speed and as appeared on device display screen. In high forward speed the amount of fuel recorded when the tractor operated with disc plough has increased by 26.45. For Claas combine harvester, data showed the significant differences of fuel consumed. Where, in low forward speed of combine harvester, amount of $6.22 \mathrm{l} / \mathrm{h}$ has been recorded, and $12.70 \mathrm{l} / \mathrm{h}$ has been consumed by combine engine but at high forward speed with standard divisions of 0.24 and 0.19 under high and low forward speed of the combine respectively.

Keywords: Fuel consumption, turbine flow meter, farm machinery' engines, fuel flow rates.

\section{INTRODUCTION}

$\mathrm{F}$ Vuel consumption plays a significant role in the selection and management of tractors and equipment. And better estimates representing actual field operations are needed to compare machinery management strategies. Depending on the type of fuel and the amount of time a tractor or machine is used, fuel and lubricant costs will usually represent at least 16 percent to over 45 percent of the total machine costs (Siemens and Bowers, 1999; Grisso et al., 2010). Fuel consumption can be measured by several methods. The simplest way is manual bookkeeping of the consumed fuel and the work done. Where, this measurement can be completed by filling the fuel tank of the tractor before and after a field operation, noting the area covered. The number of liters used, divided by the area covered, gives the fuel consumption in liter/ unit area. Even this simple method gives adequate accuracy in many cases, and it can be used as an information source for energy analysis. Other simple way to measure fuel consumed in any operation is using a 
small cylindrical fuel container branched to the main fuel line and equipped with a transparent fuel level indicator to measure fuel consumption (Natsis et al., 1999). On-line measurement can be done indirectly, for example from the exhaust gas temperature or injection needle lift duration of the machine, or directly using a fuel flow meter (McLaughlin et al., 1993). Suitability of different measuring methods depends on the use of the data and the objectives of the study. Indirect methods have been used to create an efficiency monitor to guide the driver to use the machine efficiently. The efficiency of a tractor operation can be improved often by SUTB-approach (shift up, throttle back) when not working under full load conditions (Howard et al., 2011). Pang et al., (1985) investigated the possibility of monitoring tractor efficiency by measuring the fuel consumption indirectly via the exhaust gas temperature and using an electronic correction system. De Souza and Milanez (1988) used the same method to evaluate the torque of the engine. However, the most common way to fuel consumption measurement has been the use of flow meters. This method can provide a good accuracy and it can be used for wide variety of applications. When using flow meters, the return line from the injection pump has to be either measured separately or be returned to the inlet side of the transfer pump. This may require an external cooling for the fuel in the return line. For high accuracy measurements, the fuel temperature must also be recorded in order to calculate the correct mass flow. (Domsch et al., 1999; McLaughlin et al., 1993). In modern machines the fuel consumption data can also be captured from the CAN-bus (controller area network) of the machine. The fuel consumption information can be collected from the bus data traffic with a suitable analyzer hardware and software. The advantages of this method are that no additional sensors are needed, and some other useful information can be collected simultaneously, for example the draught force of the three-point hitch link. (Schutte et al., 2004).

Jokiniemi et al. (2012) tested a simple and cost effective way to measure the fuel consumption of agriculture machinery. The fuel consumption was measured by the voltage signal of machine's own fuel level sensor. The signal was recorded with a voltage data logger, and movements of the 
machine were recorded with a simple personal GPS-tracker. They concluded that measuring system was inexpensive, easy to install and did not require any modifications to the fuel system. It can also be installed to almost any tractor or other self-propelled farm machine. However certain restrictions were found e.g. the measuring period has to be relatively long to obtain reliable results. Fathollahzadeh et al. (2011) Stated that one of the best methods to measure fuel consumption of a tractor engine is using flow meter sensors on the tractor. They used an electronic board to receive and save the digital pulses sent by the flow meter sensors. In this system, battery, monitoring unit, keyboard for controlling the operation of the system and memory for recording data in field operations were used. In spite of the capabilities of the system which can show instantaneous fuel consumption, and the easy installation steps, approximate accuracy of the system was $2 \%$, and it can be am limitation to use in some measurements where the differences are critical. Yule et al. (1999) developed a data acquisition system to monitor in-field performance of an agricultural tractor. In their research fuel consumption was measured using a MS ${ }^{\text {TM }}$ Mk4 fuel flow meter manufactured by JPS Engineering, Birmingham, England. The fuel flow meter consisted of a full flow filter, a 'demand only' fuel pump, a positive displacement flow sensor and a heavily finned fuel return tank. The energy to drive the flow sensor was provided by a slave electrical fuel pump. In this way the fuel measuring system does not influence on the tractor's standard fuelling arrangements in any way. Bedri and Al-Hashem (2006) developed an instrumentation package for monitoring tractor performance. The package included a data acquisition system and transducers for monitoring forward speed, rear wheel speed, fuel consumption and drawbar pull. They used an RS256225 turbine flow transducer to measure fuel flow rate. The transducer was connected between the main fuel tank and the injector pump for measuring the fuel flowing from the tank. The return fuel from the injector pump and the injectors was cooled via a heat exchanger placed in front of the tractor radiator and then returned to an intermediate vented fuel tank downstream from the fuel transducer. Kheiralla et al. (2007) measured tractor fuel consumption at various tillage depths and speeds by using an oval flow meter sensor located between the injector pump and 
the fuel filter, and experimental data were saved in an extra memory and were analyzed by transferring them to a computer. Also, based in such fuel meters, more contributes can be done to the assessment of on-site fuel consumption estimation and to develop a quantitative method to predict fuel consumption (Trani et al., 2016). However, there are no much detailed studies related to measuring fuel consumption using flow meter sensors. Also, very few cases recorded for measuring fuel consumption by such sensors in field operations in Egypt. So, in this study a new system was designed and calibrated to accurately measure and record fuel consumption under different condition and for different farm machines.

\section{MATERIALS AND METHODS}

To build an accurate fuel consumption measuring device, a set of functions should be exist while using it e.g.; 1) connecting and disconnecting the device to different machines should be easy as possible and do not need a specific skill; 2) the device should be able to provide the reading of consumed energy directly and on time of the operation; 3 ) recording facility of measurements and to be extracted when needed from the device; 4) the accuracy to be maximum to overcome the drawbacks of traditional available methods; and 5) the cost should be minimum and circuits, material and power sources should be available. So, a battery operated fuel consumption meter has been developed and tested to be an adequate option to measure fuel consumption of a wide range of agricultural machine working in field such as but not limited to tractors, combine harvesters, small engines.

\section{Fuel consumption measuring device: component and principals}

\subsection{Flow sensors}

A turbine flow meter is a volumetric flow metering device. The meter consists of a rotor and bearing assembly suspended on a shaft, which is mounted to a support device. This assembly is mounted inside housing with a known internal diameter and as fluid passes through the flow meter housing, the rotor will spin at a rate proportional to the volume of liquid passing through the housing. A magnetic or modulated carrier pick-off sensor is used to detect the passage of each rotor blade and generate a 
frequency output. The frequency output can be read directly with the end users electronics or further processed to convert to an analog output, linearized or compensated for temperature variations. There are several characteristics of turbine flow meters that make them an excellent choice for some applications. The flow sensing element is very compact and light weight compared to various other technologies. This can be advantageous in applications where space is a premium. So in this study, turbine flowmeter Vision 1000 sensor has been used to build the fuel consumption device. This commercial type of sensor has for very small flowrates of $0.05-2.5 \mathrm{l} / \mathrm{min}$ which is suitable for most tractors and farm machines. Specification and technical data of turbine flow sensor listed in table 1. Such turbine meters are for the exact metering of small quantities of liquids and suited for flow measurement of fuel and fuel consumption. The half effect turbine flow rate sensor is ideal for applications involving low flow liquid monitoring. In addition, the low cost coupled makes it an ideal for replacing dispensing timer systems. The sensors standard power and output specifications make it easy to retrofit with many systems as required (LICO Electronics, 2013) (Fig. 1).

Table 1 Specification and technical data of used turbine flow sensor (Turbine Flowmeter Vision 1000)

\begin{tabular}{|l|l|l|l|}
\hline \multicolumn{2}{|l|}{ Specification and technical data: } & \multicolumn{2}{l|}{} \\
\hline Measuring range & $0.05-2.5 \quad 1 / \mathrm{min}$ & Material & Trogamid (PA 12) \\
\hline Pulses per liter & 18.500 & Viscosity & $0,8-16 \mathrm{~mm}^{2} / \mathrm{sec}$ \\
\hline Size DN & $5 \mathrm{~mm}$ & Accuracy & $\begin{array}{l}3 \% \text { of momentary } \\
\text { value }\end{array}$ \\
\hline Pressure loss & 0.02 to $0.25 \mathrm{bar}$ & Repeatability & $0.50 \%$ \\
\hline Temperature range & -20 to $+100{ }^{\circ} \mathrm{C}$ & Supply & $5-24 \mathrm{VDC}$ \\
\hline & & & \\
\hline Operating pressure & Maximum 25 bar & Consumption & approximately $8 \mathrm{~mA}$ \\
\hline Electrical connection & EN 60529 & & \\
\hline
\end{tabular}




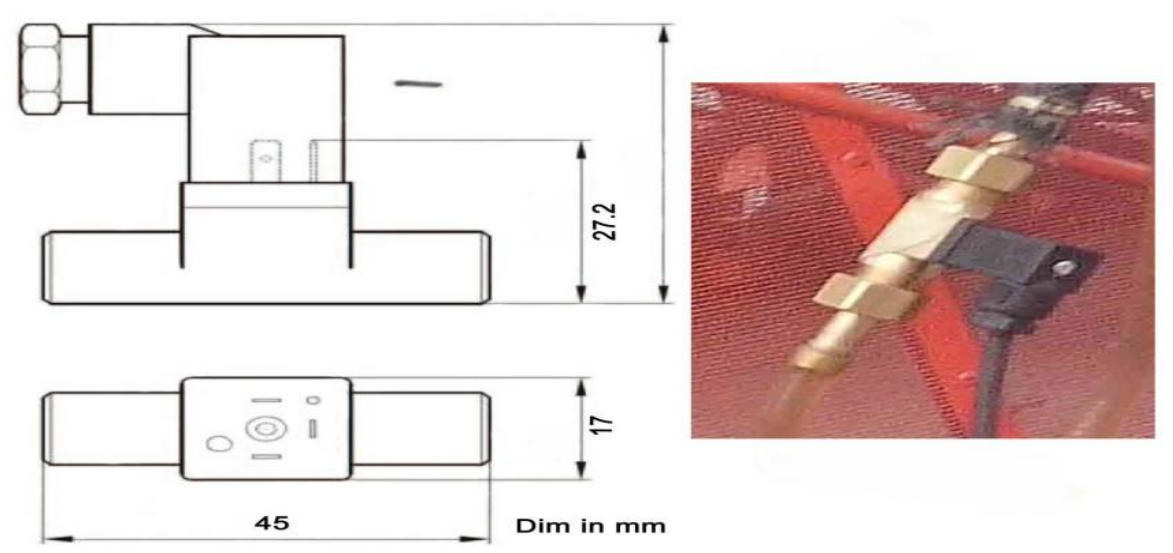

Fig. 1 Turbine flowmeter VISION 1000

\subsection{Operating principle of sensors and installment}

Fuel flow causes a bladed turbine inside its housing to turn at an angular velocity directly proportional to the velocity of the fuel measured. As the blades pass breath a magnetic pickup coil, a frequency signal is generated. Each pulse is equivalent to a discrete volume of fuel. The frequency pulse is directly proportional to the turbine angular velocity and the flow rate. The large number of pulses gives a good resolution. As the mass of the turbine are very small the response time is very short. It is not necessary to install a straight length of pipeline at the up streamside. The simple mechanical construction of the sensors guarantees a long lifespan without any loss of accuracy and pressure pulses do not affect the measuring system. In case of tractors and farm machinery over $50 \mathrm{hp}$ engines, two sensors of turbine flowmeter Vision 1000 type were used to measure the input fuel flow to the injector pump as well as the fuel returning from the injectors and the injector pump to the tank. While, in case of medium size engines one sensor is connected to the fuel line without return sensor as in Fig. 2 a, b, c and d. Installment of second type of sensor done same as above but with one sensor as the small engine similar to medium size ones of having one fuel tube.

\section{Electronic board and circuits}

Electronic board used in the study was a modified version of ATmega328 series chip which offers many digital and analog pins, it pre-loaded with the Arduino Optiboot Bootloader to allow sing Arduino code without having to use an actual Arduino board. 


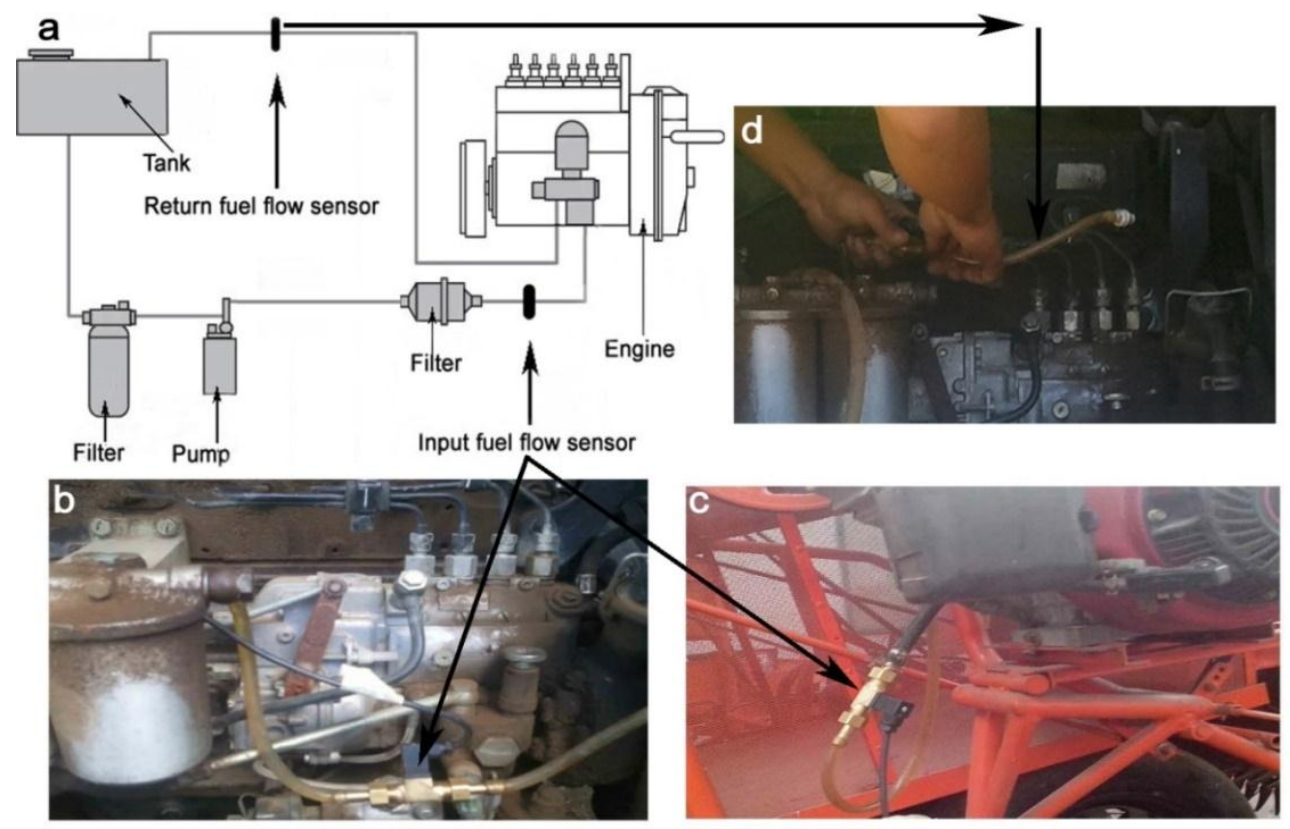

Fig. 2 a: Diagram of where the fuel sensors should be connected to input

and return fuel lines; $b$ and $d$ : Connected sensor to fuel input tube in combine harvester (58 hp CLAAS Crop Tiger); c: Connected sensor to the only fuel line in medium size $16 \mathrm{hp}$ engine

The pulses of the flow sensors are being converted into consumption and displayed. The reading of these pulses is being done for one sensor when connected alone as inlet sensor or for both sensors as inlet and return sensors according to algorithms set for that purpose. When data presented in display screen at the time of connecting two sensors, data come from the subscription of the two values as amount passed through the inlet sensor and data recorded from return sensor. Attached liquid crystal display (LCD) screen has ability to show current consumption in $1 / \mathrm{min}$ as well as total consumption in 1 . The counter contents can be deleted by a reset button and consumption data are stored on a multi capacity memory card. The extracting of data stored is being done via the USB interface and it used for coding and calibration too. The board and its components are placed in Aluminum housing and electrical connections done via waterproof connectors as shown in Fig. 3. Extra display screen has been used for more in-field measurements and can be attached and extended through additional wire when needed. Connector for the serial port has 
been located on board to develop control software and for adapting voltage level from personal computer as shown on data acquisition schematic chart (Fig. 4). There are software-module have modified for parameter control and presentation of the measured data on PC.

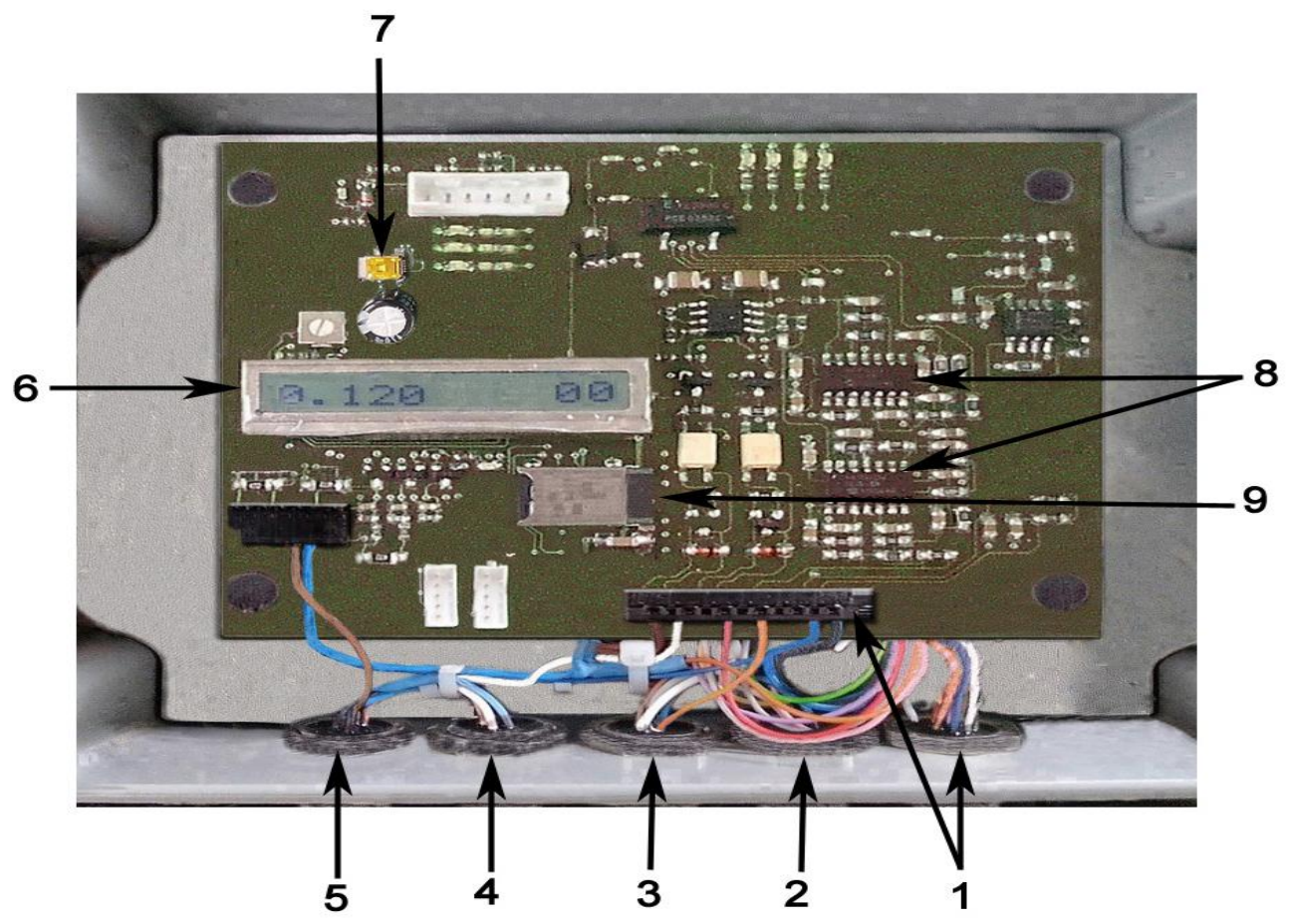

Fig. 3 Electronic board and circuits for designed fuel consumption device

1: Power input 2: Inlet sensor connection 3: Return sensor connection 4: Extended USB line 5: Extra display connection 6: Liquid crystal display (LCD) 7: USB connection 8: Micro controllers 9: Storage memory

\section{Calibration factor}

Calibration factor is the number of pulses per liter that the sensor will produce. Every sensor is individually calibrated by flowing a known volume of fuel through the meter at five different flow rates; one at the maximum rate, one at the minimum rate, and three at rates equidistantly spaced between. In the sensor we used in current research, 20000 pulses /1 was set from the manufacturer as the calibration factor at frequencies ranged from $42-833 \mathrm{~Hz}$ and $45 \mathrm{~mm}$ installation length. Along with the calibration factor, flow of fuel through the meter being calibrated is diverted into a tank of known volume. 
FARM MACHINERY AND POWER

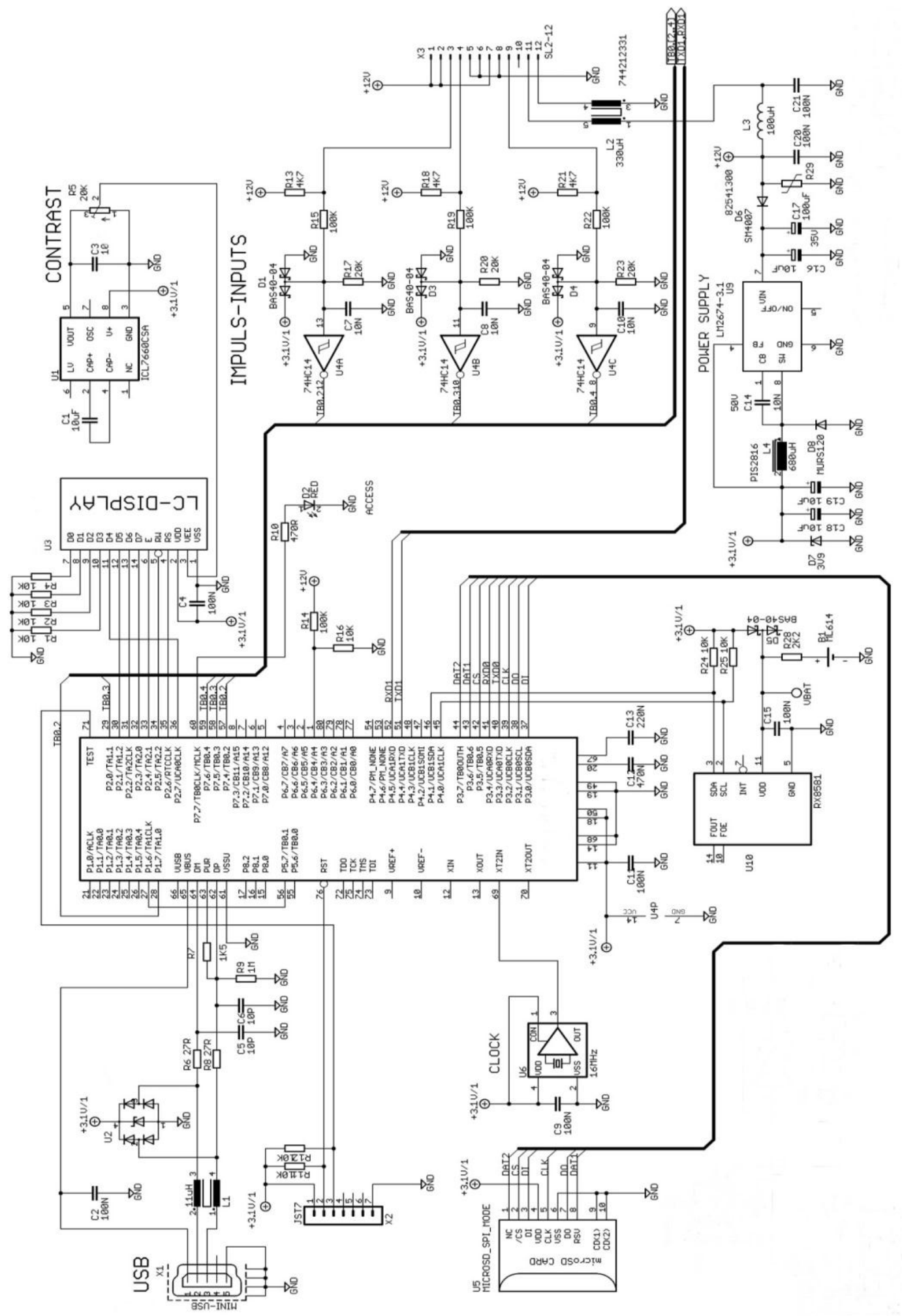

Fig. 4 data acquisition schematic chart

Misr J. Ag. Eng., October 2016 
The time to displace the known volume is recorded to get the volumetric flow rate e.g. liter per minute using external marked small tank. This flow rate can then be compared to the turbine flow meter readings, and the accuracy with repeatability of each sensor can be calculated based on these differences under different conditions as in equation 1. For in-door lab testing and measurements, $110 \mathrm{hp} \mathrm{New} \mathrm{Holland} \mathrm{tractor} \mathrm{and} \mathrm{a} 16 \mathrm{hp}$ medium size engine have been used for tracing the accuracy and differences of using fuel consumption device at stationery mode without moving but with throttle variation. During in-door testing, regression equations for real volume of fuel flow and volume measured by the fuel flow device have been generated.

$$
\mathbf{e}=\frac{|\mathbf{V v}-\mathbf{V s}|}{\mathbf{V v}}
$$

Where; e $=$ Measurement error, $\%, \mathrm{~V}_{\mathrm{v}}=$ Real volume of fuel flow, $1 / \mathrm{min}$., and $V_{s}=$ Volume measured by the fuel flow device, $1 / \mathrm{min}$.

\section{Field testing}

In field, the fuel consumption device attached to two different machines, a $58 \mathrm{hp}$ Claas combine harvester where all moving parts were engaged and the machine was tested on ground with no crop. Second farm machine was the New Holland tractor $110 \mathrm{hp}$ running in field alone and loaded with disc plough, to show the differences appear during different conditions for more reliability for fuel measurement device. All different loaded and unloaded experimental tests carried out in experimental farm in faculty of agriculture, Kafrelsheikh University during the period from June to July 2016 while the manufacturing of the device started in 2015. During field test the device attached to the machine frame and sensors connected to the fuel tubes. An extra display screen has been attached and can be hand held to be able to read the current measurements (Fig. 5). Data from fuel consumption device has been noted in specific time either for one sensor or two sensors. Also, each tested machine has run under two different speeds as high and low speed to see the variation of fuel with forward speeds. 


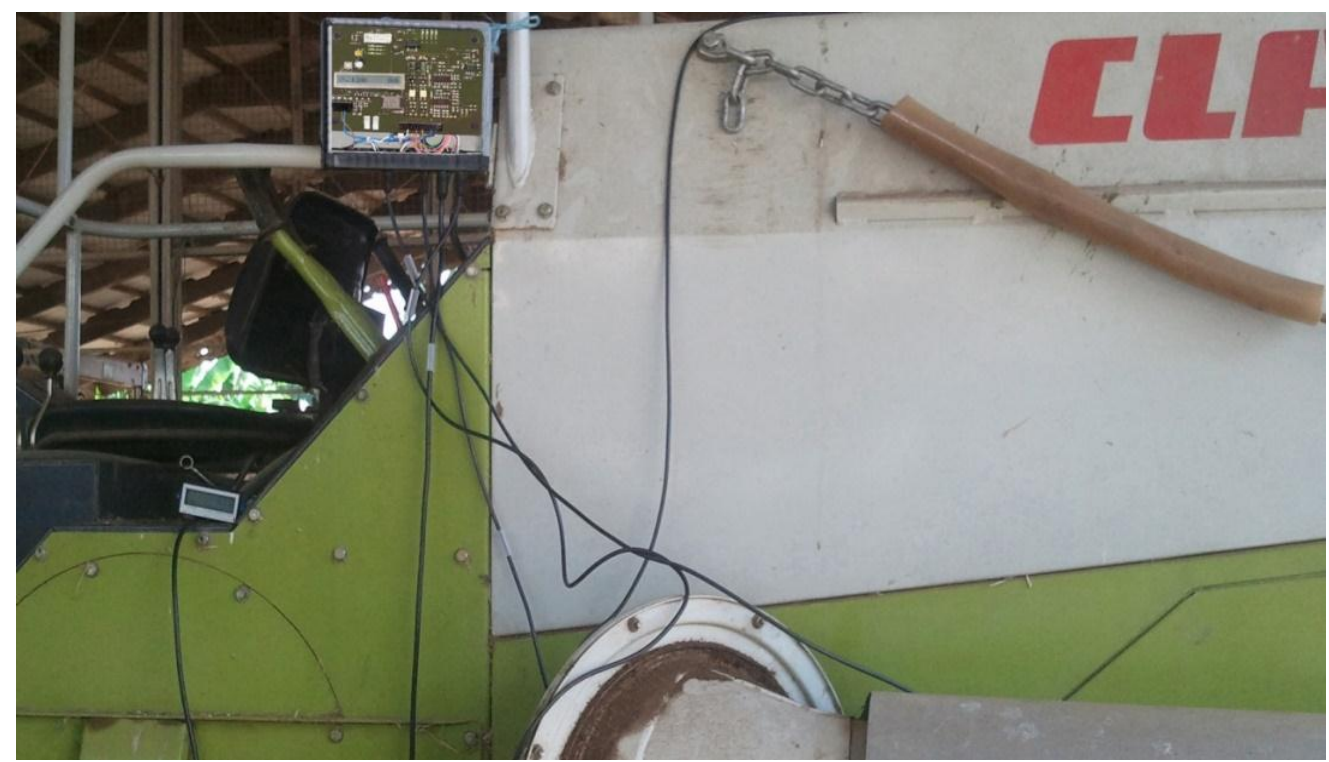

Fig. 5 Attaching fuel consumption device and extra display screen to Claas combine harvester for field testing

\section{RESULT AND DISCUSSION}

\section{Accuracy and repeatability of sensors used in fuel consumption device}

Regression equations for real volume of fuel flow and volume measured by the fuel flow device have been generated from data recorded when different machine operated, while under same condition, the actual amount observed as real volumetric consumption too to see how far the data generated from fuel consumption from the real consumed amount. For New Holland tractor with $110 \mathrm{hp}$ running at full throttle position, the average fuel consumption recorded on the device display was $0.602 \mathrm{l} / \mathrm{min}$. While the average of amount observed and consumed by the engine was $0.597 \mathrm{l} / \mathrm{min}$. There were acceptable linear relationships between real volumetric consumption of fuel flow and volume measured by the fuel flow device with $0.8 \%$ differences between averages (Fig. 6a). Same tractor with lower throttle position gave $0.16 \%$ differences between average data recorded with connected device and real volumetric flow of fuel (Fig. 6b). In general the fluctuation in the flow of fuel recorded by the device was very low and the readings were quit stable. 


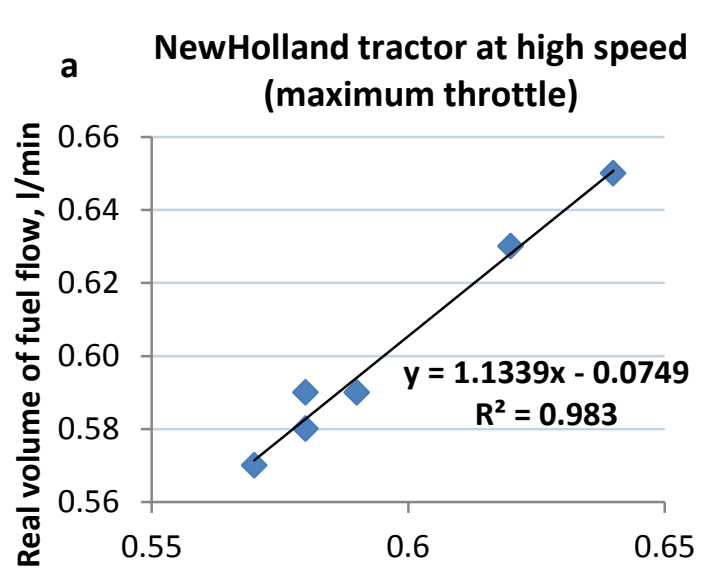

Volume by fuel consumption device, $1 / \mathrm{min}$ b

NewHolland tractor at high speed (lower throttle position)

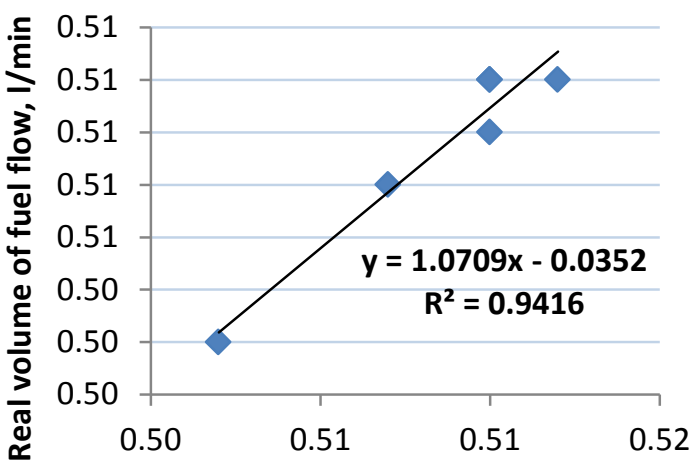

Volume by fuel consumption device, $1 / \min$

Fig. 6 Regression equations for real volume of fuel flow and volume measured by the fuel flow device connected to New Holland tractor

For $16 \mathrm{hp}$ engine tested in lab, the differences were higher and around 1.5 $\%$ and $2.4 \%$ in case of running the engine at full throttle and lower throttle position respectively (Fig. $7 \mathrm{a}$ and b).

The displayed reading on screen which was 0.080 and $0.0831 / \mathrm{min}$ for the $16 \mathrm{hp}$ engine at higher and lower throttle positions respectively was very close the recommended minimum volume that the sensor connected to device can record. That is may be the reason that variation was higher than using the sensor with tractor and it is better to avoid such sensors with smaller engines.

$16 \mathrm{hp}$ engine at high throttle position

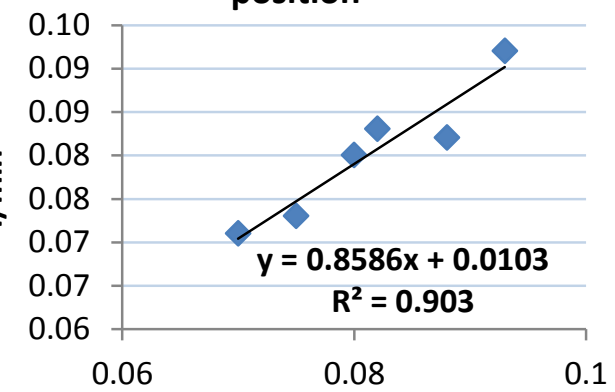

Volume by fuel consumption device, $1 / \mathrm{min}$ b $\quad 16 \mathrm{hp}$ engine at lower throttle

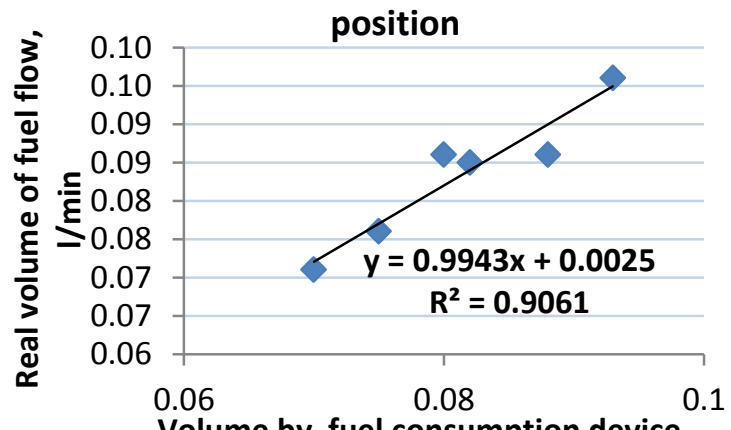

Volume by fuel consumption device, $1 / \mathrm{min}$

Fig. 7 Regression equations for real volume of fuel flow and volume measured by the fuel flow device connected to $16 \mathrm{hp}$ engine. 


\section{In-Field testing}

Testing of developed fuel consumption device done in field by connecting it to two different machine i.e. New Holland tractor and Claas combine harvester. For recording the tractor fuel consumption as application of the fuel measuring device, data has been recorded under two forward speeds as high and low speed. For each speed the tractor has run in field for specific time and the fuel consumption recorded by the device has been noted. Same experiments repeated but with loading the tractor by connecting a disc plough to observe the differences of fuel reading in each case. Data presented in table 2 show that and by logic, increasing both forward speed of tractor used in the study and load equipped with it increased fuel consumption. Where, attaching the rotavator to the tractor increased the fuel consumed by the engine by $20.75 \%$ at low tractor speed and as appeared on device display screen. In high forward speed the amount of fuel recorded when the tractor operated with disc plough has increased by $26.45 \%$.

Average values of fuel consumed by the engine recorded under low and high forward speed were 13.06 and $14.10 \mathrm{l} / \mathrm{h}$ with standard division of 0.01 and 0.521 in unloaded condition respectively. While, the amount consumed by the engine when the tractor loaded was 16.48 and $19.17 \mathrm{l} / \mathrm{h}$ for low forward and high forward speed with standard division 0.863 and 0.585 respectively (Fig. 8 ).

For Claas combine harvester as big engine self-propelled farm machine, the device has been attached and tested to record the fuel consumption when the combine harvester run under low and high speed and average data showed the significant differences of fuel consumed. Where, in low forward speed of combine harvester, amount of $6.22 \mathrm{l} / \mathrm{h}$ has been recorded, and $12.70 \mathrm{l} / \mathrm{h}$ has been consumed by combine engine but at high forward speed. In both cases, the combine was ruing on field road and all parts engaged but without crop table 3 and. Standard divisions of data recorded were 0.24 and 0.19 under high and low forward speed of the combine (Fig. 9) 
Table 2 data recorded by the fuel consumption device under different experimental conditions for tested tractor.

\begin{tabular}{|c|c|c|c|c|c|c|c|c|c|c|}
\hline $\begin{array}{l}\text { कूँ } \\
\text { के }\end{array}$ & فَّ & 莺 & 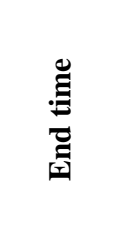 & 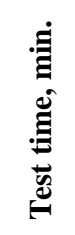 & & & 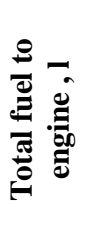 & 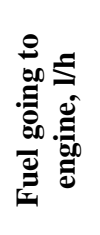 & 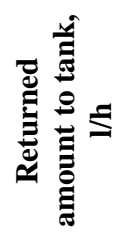 & 胥言 \\
\hline \multirow{3}{*}{ Slow } & \multirow{3}{*}{ 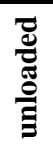 } & $10: 45$ & 10:49:04 & 4.06 & 24.86 & 27.07 & 2.21 & 32.66 & 19.59 & 13.07 \\
\hline & & 11:00 & 11:05:30 & 5.50 & 32.06 & 35.05 & 2.99 & 32.62 & 19.57 & 13.05 \\
\hline & & $11: 10$ & $11: 15$ & 5.00 & 36.14 & 38.86 & 2.72 & 32.64 & 19.58 & 13.06 \\
\hline \multicolumn{2}{|c|}{ Average } & & & & & & & & & 13.06 \\
\hline \multirow{3}{*}{ Slow } & \multirow{3}{*}{ 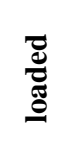 } & $2: 12$ & $2: 16: 48$ & 4.80 & 8.48 & 11.68 & 3.20 & 40.00 & 24.00 & 16.00 \\
\hline & & $2: 20: 08$ & $2: 24: 17$ & 4.20 & 14.04 & 17.10 & 3.06 & 43.71 & 26.23 & 17.48 \\
\hline & & $2: 30$ & $2: 35: 30$ & 5.50 & 20.60 & 24.26 & 3.66 & 39.93 & 23.96 & 15.97 \\
\hline \multicolumn{2}{|c|}{ Average } & & & & & & & & & 16.48 \\
\hline \multirow{3}{*}{ High } & \multirow{3}{*}{ 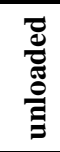 } & 11:20:10 & $11: 24: 18$ & 4.13 & 41.04 & 43.53 & 2.49 & 36.17 & 21.7 & 14.68 \\
\hline & & 11:49:28 & $11: 51: 30$ & 2.03 & 55.26 & 56.46 & 1.20 & 35.48 & 20.93 & 13.95 \\
\hline & & $13: 25$ & $13: 29: 24$ & 4.40 & 75.40 & 78.09 & 2.69 & 36.68 & 22.01 & 13.67 \\
\hline \multicolumn{2}{|c|}{ Average } & & & & & & & & & 14.10 \\
\hline \multirow{3}{*}{ High } & \multirow{3}{*}{ 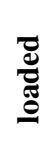 } & $3: 31: 18$ & $3: 36: 29$ & 5.20 & 40:95 & 44.98 & 4.03 & 46.5 & 27.09 & 18.60 \\
\hline & & $3: 40: 15$ & $3: 45: 00$ & 4.75 & 50.18 & 53.97 & 3.79 & 47.87 & 28.72 & 19.15 \\
\hline & & 4:00 & 4:04:09 & 4.15 & 63.80 & 67.22 & 3.42 & 49.44 & 29.67 & 19.77 \\
\hline \multicolumn{2}{|c|}{ Ave } & & & & & & & & & 19.17 \\
\hline
\end{tabular}

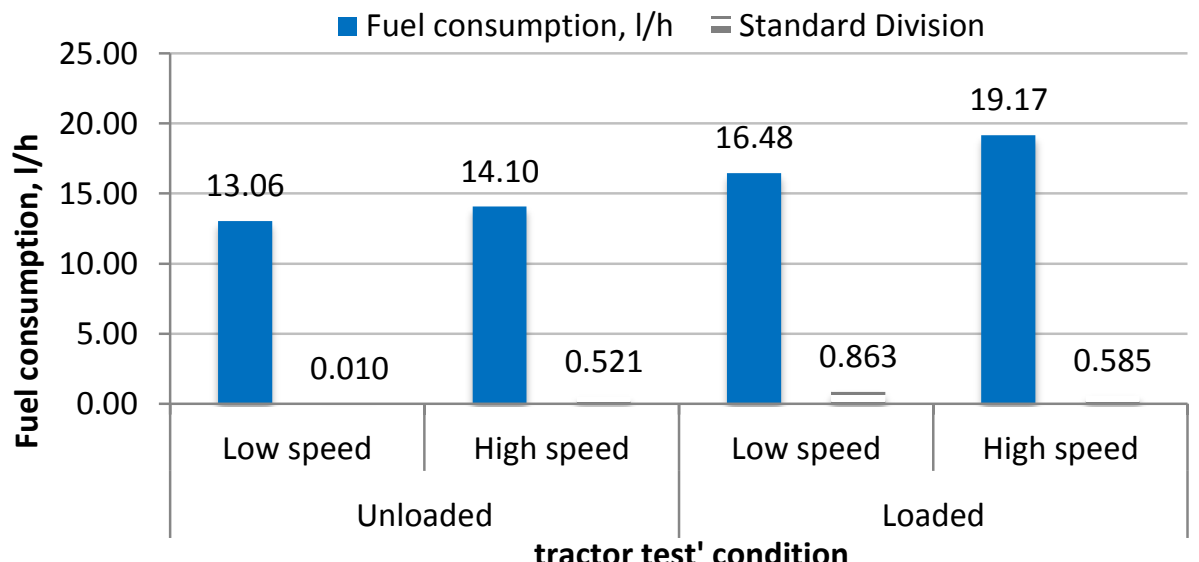

Fig. 8 Average fuel consumed by tractor engine in different test condition 
Table 3 Data recorded by the fuel consumption device under different experiments conditions for combine harvester.

\begin{tabular}{|l|c|c|c|c|}
\hline \multicolumn{1}{|c|}{ Speed } & Time, $\mathbf{m i n}$ & $\begin{array}{c}\text { Initial } \\
\text { reading, } \mathbf{l}\end{array}$ & $\begin{array}{c}\text { Final reading, } \\
\mathbf{l}\end{array}$ & $\begin{array}{c}\text { Actual Fuel } \\
\text { consumption, } \\
\mathbf{1 / h}\end{array}$ \\
\hline \multirow{3}{*}{ High speed } & 10.00 & 4.08 & 6.16 & 12.48 \\
\cline { 2 - 5 } & 10.00 & 7.28 & 9.39 & 12.66 \\
\cline { 2 - 5 } & 10.00 & 10.47 & 12.63 & 12.96 \\
\hline Average & \multicolumn{3}{|c|}{$\mathbf{1 2 . 7 0}$} \\
\hline \multirow{3}{*}{ Low speed } & 10.00 & 13.90 & 14.96 & 6.36 \\
\cline { 2 - 5 } & 10.00 & 15.08 & 16.13 & 6.30 \\
\cline { 2 - 5 } & 10.00 & 0.69 & 17.46 & 6.00 \\
\hline Average & \multicolumn{3}{|c|}{$\mathbf{6 . 2 2}$} \\
\hline
\end{tabular}

$\triangle$ Fuel consumption, $\mathrm{l} / \mathrm{h} \quad$ Standard Division

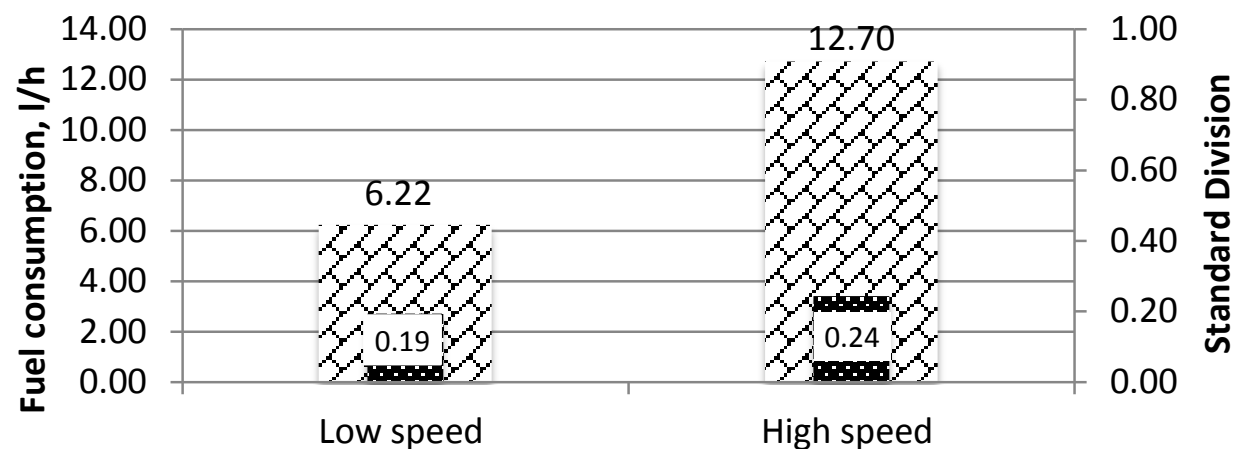

Combine Harvester' forward speed

Fig. 9 Average fuel recorded by combine harvester and values' standard division

\section{Total cost}

The major cost which directed to build the fuel flow meter was the flow sensors which were imported; all other components used in the device can be easily purchased from local stores. However, the cost is consider high compared to the manual measurements, but the accuracy and the reliability of the device applications make this price is reasonable. On the other hand, the ready purchased fuel meters are much higher in price and don't fit all agricultural engineering measurements and not easy to rely on it in such measurements. The summery of device elements' cost are mentioned in table 4 . 
Table 4 device' elements cost

\begin{tabular}{|l|c|l|}
\hline \multicolumn{1}{|c|}{ Elements } & $\begin{array}{c}\text { Price } \\
\text { in EP }\end{array}$ & \multicolumn{1}{c|}{ Notes } \\
\hline Flow sensors & 2800 & Imported and no local items available \\
\hline Software module & 850 & $\begin{array}{l}\text { Can be eliminated if the skills to build } \\
\text { one are available }\end{array}$ \\
\hline Local display screen & 110 & \\
\hline Aluminum housing & 80 & \\
\hline Wire, connectors extensions & 400 & \\
\hline USB-port and SD card & 100 & \\
\hline $\begin{array}{l}\text { Electronic board and circuits with } \\
\text { built in screen and diodes }\end{array}$ & 450 & \\
\hline Total (in EP) & 4790 & \\
\hline
\end{tabular}

\section{EG : Egyptian pound}

\section{CONCLUSION}

Manufacturing such fuel meters can enhance the measurements of fuel under different conditions in labs as well as in field testing. All materials to build such flow meter are available and include local materials but with importing the sensors as they are not available locally yet. the price is consider reasonable to manufacture the fuel flow device compared to the price to get it ready from companies and it doesn't need specific skill either in the installation or in using it. The device can be used in wide range of activities with different engines but more than $16 \mathrm{hp}$ and its accurate compared to any other local methods. differences between the real precise volumetric consumption and volume measured by the fuel flow device was acceptable and reached $2.4 \%$ in case of using medium size engines of $16 \mathrm{hp}$, and was less with bigger engines. In field testing, the device recorded fuel consumed by different engines to show the consumption behavior under different condition and the results were clear under each testing situation. It was difficult to find sensors that have wider range for measuring fuel consumption of amount less than 0.05 $1 / \mathrm{min}$, so other fuel flow sensors should be used in case smaller engine are used in field operation and subjected to fuel test. Furthermore, best possible accuracy over wide temperature and flow ranges should be tested.

\section{REFERENCES}

Bedri, A. R A. and H A. S. Al-Hashem (2006). High Precision Instrumentation Package for Monitoring the Tractor Performance. Scientific Journal of King Faisal University: Basic and Applied Sciences 7, p: 95- 106. 
Trani, M. L, B. Bossi, M. Gangolells, and M. Casals (2016). Predicting fuel energy consumption during earthworks. Journal of Cleaner Production 112, Part 5, 20: 3798-3809.

De Souza, E. G. and L. F. Milanez (1988). Indirect Evaluation of the Torque of Diesel Engines. Transactions of the ASAE 31, 13501354.

Domsch, H., D. P. Ehlert, A. S. Smrikarov and N.V. Bentscheva (1999). Fuel consumption measurement with agricultural machinery. Landtechnik 54, 278-279. European Space Agency (ESA) 2009. EGNOS: European geostationary

Fathollahzadeh, H., H. Mobli, A. Jafari, D. Mahdavinejhad, S.M.H. Tabatabaie (2011). Design and calibration of a fuel consumption measurement system for a diesel tractor. Agricultural Engineering International: the CIGR Journal. Manuscript No.1408. Volume 13, Issue 2, p: 1:12.

Grisso R., J. V. Perumpral, D. Vaughan, T. R Gary, R. Pitman (2010). Predicting Tractor Diesel Fuel Consumption. PUBLICATION 442073. Communications and Marketing, College of Agriculture and Life Sciences. Virginia Polytechnic Institute and State University, Petersburg. USA. P: 1-10.

Howard, C. N., M. F. Kocher, R.M. Hoy and E.E. Blankenship (2011). Testing Fuel Efficiency of Tractors with both Continuously Variable and Standard Geared Transmissions. ASABE Meeting Presentation, paper number: 1110971.

Jokiniemi1, T., H. Rossner and J. Ahokas (2012). Simple and cost effective method for fuel consumption measurements of agricultural machinery. Agronomy Research Biosystem Engineering, Special Issue 1, p: 97-107.

Kheiralla, A. F., A. Yahya, M. Zohadie, and W. Ishak (2007). Modelling of power and energy requirements for tillage implements operating in Serdang sandy clay loam, Malaysia. Soil \& Tillage Research 78, 21-34.

LICO Electronics (2013). Turbine Flowmeter Vision 1000. LICO Electronics GmbH, A-2320 Kledering. LICO Hungaria Kft, H-2030 Erd. LICO Mecatronic, RO-540526 Targu-Mures. Available at: www.platon-direct.eu. 
McLaughlin, N. B., C. F. Drury, W. D. Reynolds, X.M. Yang, Y.X. Li, T. W. Welacky and G. Stewart (2008). Energy inputs for conservation and conventional primary tillage implements in a clay loam soil. Transactions of the ASABE 51, 1153-1163.

Natsis, A., G. Papadakis, and J.Pitsilis (1999). The Influence of Soil Type, Soil Water and Share Sharpness of a Mouldboard Plough on Energy Consumption, Rate of Work and Tillage Quality. J. Agric. Engng Res 72, 171-176.

Pang, S.N., G. C. Zoerb and G. Wang (1985). Tractor monitor based on indirect fuel measurement. Transactions of the ASAE 28, 994-998.

Schutte, B., L. Herrmann, M. Schreiber and H. D. Kutzbach ( 2004). Mapping Fuel Consumption. Additional Information on Precision Agriculture. Landtechnik 59, 152-153.

Siemens, J. C., and W. W. Bowers (1999). Machinery Management: How to Select Machinery to Fit the Real Needs of Farm Managers. Farm Business Management Series. Davenport, Iowa: John Deere Publishing.

Yule, I. J., G. Kohnen and M. Nowak (1999). A tractor performance monitor with DGPS capability. Computers and Electronics in Agriculture, 23, 155-174.

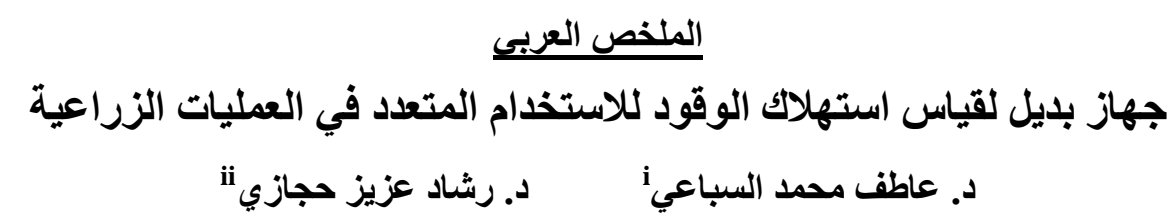

قياس استهلاك الوقود للآلات المختلفة له اهميتة ويعتبر خطوة رئيسية لاي نشاط يتبع استخدام

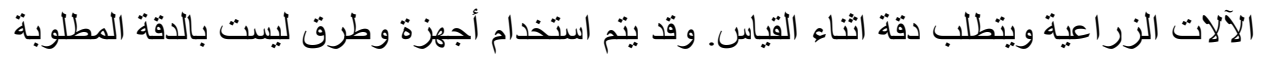

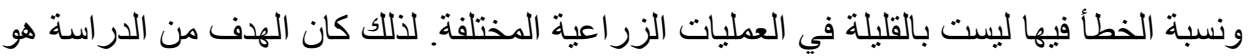

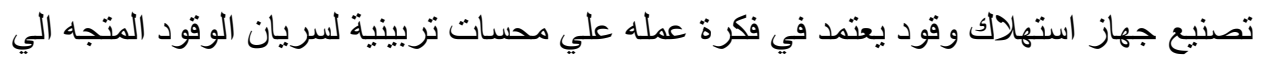

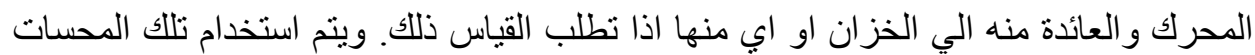

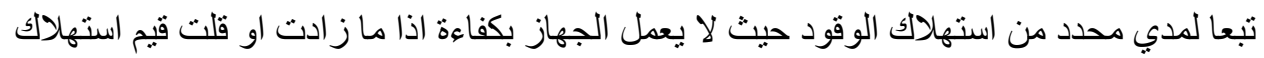

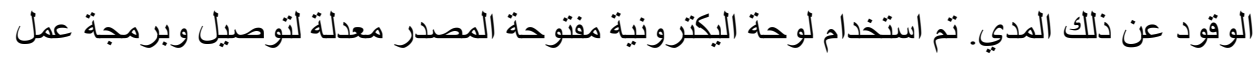
المحسات المستخدمة وتحتوي علي ميكروكنترول Microcontroller ، صمامدات ثنائية

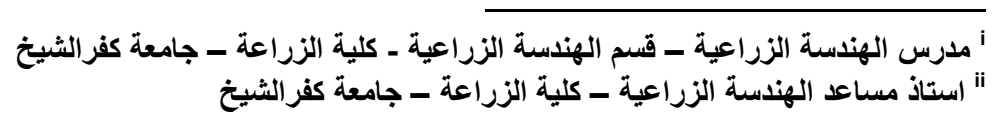


و مقاومات ، مخارج قياسية ورقمية بالاضافة الي شاثنة عرض ومخرج ناقل تسلسلي لاجهزة الحاسب. تم الاستعانة ايضا بشاثة خارجية لاظهار ما يتم تسجيلة اثناء القياس في الحقل مصدر

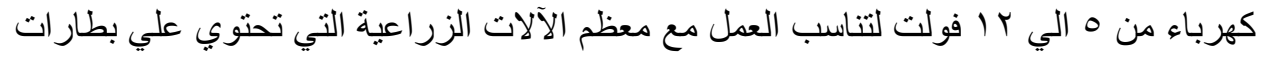

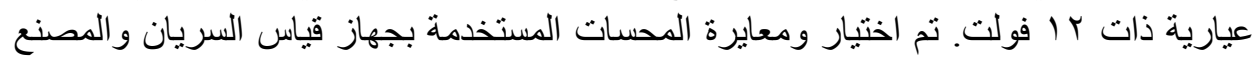
خصيصاً لتحديد كمية الوقود المار في وحدة الزمن. و انقسمت التجارب التي قسمين، القسم الاول

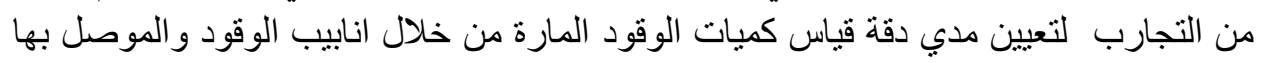

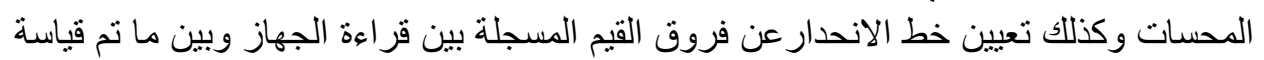
بجهاز المعايرة. وفي تللك التجارب تم استخدام محركيين احدهما قدرتة ـ 11 حصدان ولجرار

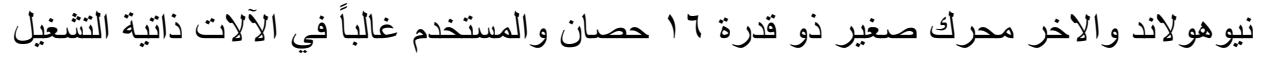

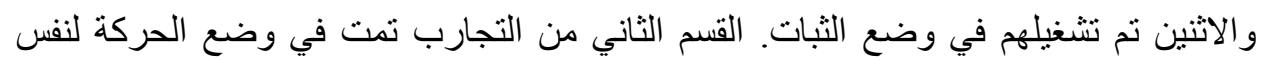

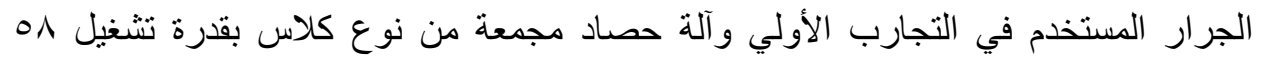
حصان. القسم الثاني من التجارب تمت تحت ظروف تشغيل مختلفة حيث تم قياس الوقود

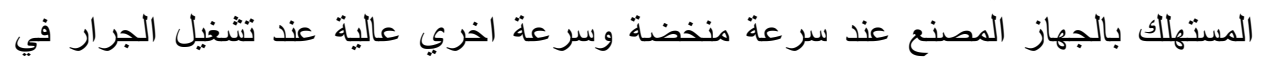

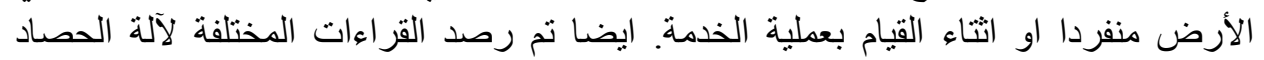
المجمعة اثناء تشغيلها ولكن في ارض غير ممهدة وبدون محصول وفي كلا ظروف التشغيل تم حساب الفروق في استهلاك الوقود وكذلك قيم الاختلاف عن المكررات لكل حالة. أظهرت النتائح

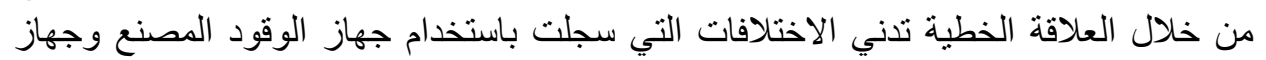

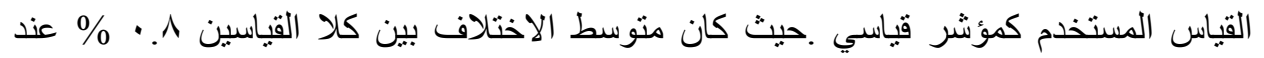
تشغيل الجرار مع اقصي كمية وقود يسمح بها صمام الخانق بينما قل متوسط الفروق المسجلة ليصل الي 1 ا. • \% عند وضع تغذية الوقود العادي مع قيم بسيطة سُجلت كانحر اف معياري للمكرر ات. في التجارب الحقلية ولملاحظة تغير كمية الوقود مع تغير الاحمال وظروف فئ التشغيل،

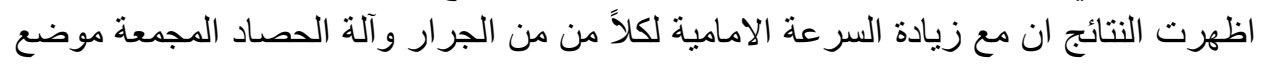

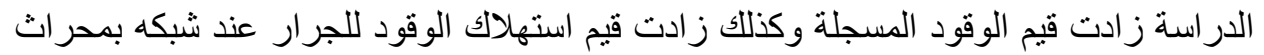

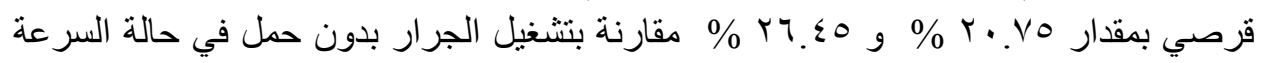

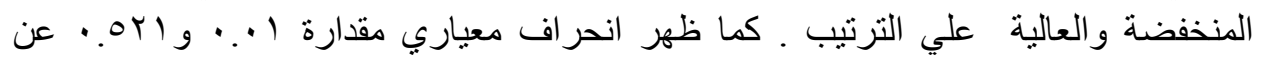
متوسط القيم المسجلة لاستهلام الجرار بدون حمل للسرعات المنخفضة و العالية علي الترتيب.

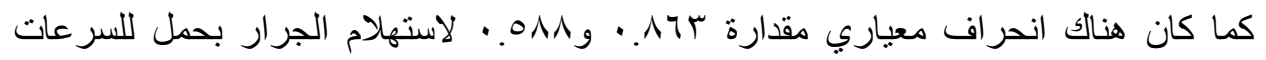

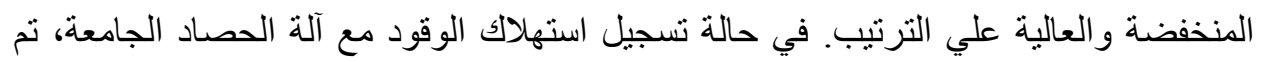

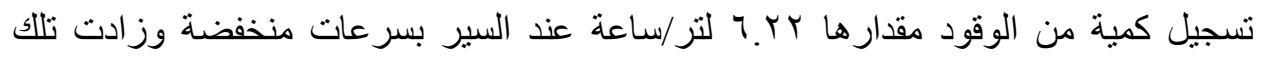

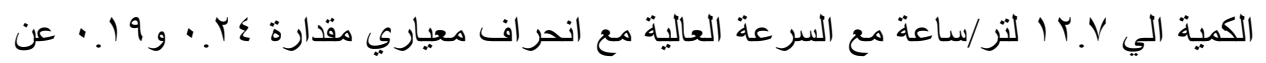

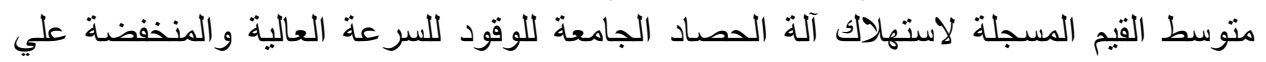
الترنيب. 